States differences in the life expectancy of white and black people have also recently increased, ${ }^{16}$ in concert with widening differentials in their incomes. ${ }^{17}$

The limited data that exist on cross national comparisons of inequalities in income and inequalities in health suggest that the two covary..$^{18}$ Furthermore, both cross sectional and time series analyses indicate that, for a given overall prosperity, countries with smaller differentials in income experience lower infant mortality and higher life expectancy..$^{190}$ Inequitable distribution of wealth may, therefore, be detrimental to the overall health profile of a country, not just to the health of an increasingly poor and disenfranchised minority.

If this is the case it is surprising that The Health of the Nation paid such scant attention to socioeconomic differentials-or "variations" (in its terminology) - in health. These variations are seen to result from "the complex interplay of genetic, biological, social, environmental, cultural and behavioural factors." ${ }^{21}$ This perceived complexity seems to be used to justify the lack of activity aimed at reducing inequalities. As Eames and colleagues point out, their research "does not prove that the association between deprivation and mortality is causal."2 Indeed, attempting to explain inequalities in any simple sense may be futile, while the concept of "cause" used in its usual epidemiological sense is probably inadequate.

This should not, however, blind us to some simple regularities. Increasing inequalities in mortality have occurred against a backdrop of large temporal and geographical variations in mortality. Differences in degree of material wellbeing can account for mortality differentials between poor and rich countries; for general reductions in mortality over long periods, as happened in Britain over the past 150 years; as well as for mortality differentials, and trends in these differentials, within countries. When some commentators attempt to reduce higher death rates among manual classes to "cultural patterns of behaviour" such as smoking and diet, they seem to lose sight of this fact. Inequalities in health were considerable at a time when, if anything, it was better off people who smoked more, consumed a higher fat diet, and engaged in little physical activity. Any increasing social polarisation of such activities may exacerbate the gradients of health differentials; they are not, however, their root cause.

Exactly those groups who have been subjected to cuts inor reduced access to-benefits, to casualisation of work, to unemployment, and to changing tax policy, have now been taken to task for their predicament. At the Conservative party's recent conference it was easy to get the impression that lone mothers-the group that has fared worst economically since 1979 - have replaced the (rapidly disappearing) miners as the enemy within. This sits uneasily with Mr Major's vision of a classless society, brought about by social mobility and "the capacity of everyone to have the help necessary to achieve the maximum for their ability." 22 With regard to allowing everyone the opportunity of achieving the maximum healththe "be all you can be" so beloved of health promoters-a reversal in the dramatic upwards redistribution in wealth is what is required.

Department of Public Health,

Senior lecturer in epidemiology and public health

University of Glasgow,

Glasgow G12 8RZ

MATTHIAS EGGER

Department of Social and Preventive Medicine,

Senior research fellow

University of Berne,

CH-3012 Berne,

Switzerland

1 Carr-Saunders AM, Caradog Jones D. A survey of the social structure of England and Wales. Oxford: Clarendon Press, 1937.

2 Eames $M$, Ben-Shlomo Y, Marmot MG. Social deprivation and preventive mortality: regional comparison across England. BMF 1993;307:1097-102.

3 Le Fanu J. A phantom carnage. The myth that low income kills. London: Social Affairs Unit, 1993.

4 Salter B. Public image limited. Health Services fournal 1991;103:28-9.

5 Department of Health. The health of the nation: a consultative document for health in England. London: HMSO, 1991.

6 Pamuk ER. Social class inequality in mortality from 1921 to 1972 in England and Wales. Population Studies 1985;39:17-31.

Wilkinson RG. Class mortality differentials, income distribution and trends in poverty 1921-1981. fournal of Social Policy 1989;18:307-35.

8 Lahelma E, Valkonen T. Health and social inequalities in Finland and elsewhere. Soc Sci Med 1990;31:257-65.

9 Townsend P, Phillimore P, Beattie A. Health and deprivation: inequality and the north. London: Croom Helm, 1988.

10 Forwell GD, Glasgow's health: old problems-new opportunities. A report by the director of public health.

Glasgow: Department of Public Health, 1993.

11 Oppenheim C. Poverty: the facts. London: Child Poverty Action Group, 1993.

12 Department of Social Security. Households below average income. A statistical analysis 1979-1990/91. London: HMSO, 1993.

13 Plotnick RD. Changes in poverty, income inequality, and the standard of living in the United States during the Reagan years. Int $f$ Health Serv 1993;23:347-58

14 Feldman JJ, Makuc DM, Kleinman JC, Cornoni-Huntley J. National trends in educational differences in mortality. Am f Epidemiol 1989;129:919-33.

15 Pappas G, Queen S, Hadden W, Fisher G. The increasing disparity in mortality between socioeconomic groups in the US, 1960-1986. N Engl f Med 1993;329:103-9.

16 Rogers RG. Living and dying in the USA: sociodemographic determinants of death among blacks and whites. Demography 1992;29:287-303.

17 Hacker A. Two nations: black and white, separate, hostile, unequal. New York: Ballantine, 1992.

18 Davey Smith G, Bartley M, Blane D. The Black report on socioeconomic inequalities in health 10 years on. $B M \mathcal{F} 1990 ; 301: 373-7$.

19 Wilkinson RG. Income distribution and life expectancy. BMF 1992;304:165-8.

20 Wennemo I. Infant mortality, public policy and inequality - a comparison of 18 industrialised countries 1950-85. Sociology of Health and Ilness 1993:15:429-46.

21 Department of Health. The health of the nation: a strategy for health in England. London: HMSO,

22 Edgell S. Class. London: Routledge, 1993.

\title{
Childhood drownings: who is responsible?
}

\section{Governments should act}

"Where were you when your child drowned?" the mother of a drowned child was asked at a public forum in Sydney last year after she had spoken in favour of legislation making fencing around swimming pools compulsory. This exchange illustrates the polarised nature of the debate over child safety: is it solely parents' responsibility to keep their children safe or does a government have a right, or indeed an obligation, to require certain safety standards in the community? This dilemma is not confined to drowning in swimming pools but encompasses many issues concerning the safety of children and adults.

Drowning is an important cause of death in childhood in developed countries such as Australia, New Zealand, the United States, Canada, and Britain; in some countries it is the main cause of death between the ages of 1 and $4 .{ }^{1-4}$ For every death from drowning there are an estimated six to 10 cases of near drowning requiring admission to hospital. Between $5 \%$ and $20 \%$ of these children will suffer neurological sequelae. ${ }^{56}$ Children drown at various sites, including swimming pools, rivers, creeks, dams, and the sea, and in baths and buckets. The leading site of drowning in young children is domestic swimming pools, with natural areas of water assuming more importance as age increases. Although different sites of drowning offer a range of preventive opportunities, some common principles can be identified.

Risk factors for childhood drowning can be divided into three categories relating to the child, parental, and environ- 
mental. ${ }^{7}$ Children under 5 are particularly at risk of immersion because their increased mobility is not matched by an awareness of risk. Although older children are more able to recognise risk, they may not be sufficiently informed about particular hazards, such as dangerous undercurrents at the beach or submerged debris in rivers. While older children can and should be taught to swim, young children cannot be relied on to save themselves, despite dubious claims about the effectiveness of "drownproofing" classes for young children. ${ }^{8}$

Parental awareness of the risks of injury to children and parental supervision are vital components of child safety, as of course is a knowledge of first aid. But the fact that drownings continue despite widespread publicity campaigns confirms that extolling parents and the public at large to "be careful" or "always supervise your child" are of limited use. Indeed, they may serve only to attribute blame. ${ }^{910}$ Realistically, parents cannot be vigilant all of the time, and it is during periods of parental distraction that children are most at risk of drowning. This suggests the need for secondary measures of protection against hazards.

Passive safety measures that require little or no action on the part of individual people underpin the current theory and practice of preventing injury. ${ }^{11}$ Commonly, passive child safety entails separating the child from the hazard. This is particularly effective in preventing childhood drownings as areas of water can be identified and, where feasible, a barrier erected. Regulatory or legislative measures may be necessary to ensure universal coverage of hazards, particularly when they are on private property.

Common sense, supported by evidence, ${ }^{12} 13$ shows that fences provide protection from drowning in domestic swimming pools. Such a barrier needs to separate the pool not only from neighbours and the street but also from the housea four sided isolation fence-as over $90 \%$ of toddlers who drown in domestic swimming pools are either residents of the house or invited guests. ${ }^{12}$ Maintaining pool fences and self closing gates to ensure that they remain an effective barrier must be a focus of preventive campaigns. This must be coupled with education regarding the dangers of propping open the gate or allowing young children to swim unsupervised. ${ }^{14}$
Several state governments in Australia have recently debated legislation requiring four sided isolation fencing. This has been a contentious issue, with health professionals urging legislation to ensure the provision of safe environments for children. Opponents have argued from a civil libertarian platform, decrying laws that affect their own backyards as draconian and an infringement of their rights. Some even claim that legislation for child safety is ineffective, that parental supervision is the only preventive option. But the success of past legislation for child restraints in motor vehicles, bicycle helmets, and numerous safety requirements embodied in building codes and product safety standards attests to the appropriateness of regulatory requirements for safety, whether on the roads, in the home, or in the backyard. In addition, community expects government intervention to ensure that children are safe from both intentional injuries, such as child abuse, and unintentional injuries, such as drowning.

\section{VICTOR F CAREY}

Director

Childsafe NSW Injury Surveillance Unit,

Children's Hospital,

Camperdown,

New South Wales 2050,

Australia

1 Nutbeam D, Wise M, Bauman A, Harris E, Leeder S. Goals and targets for Australia's health in the year 2000 and beyond. Sydney: Australian Government Publishing Service, 1993.

Kemp A, Sibert JR. Drowning and near drowning in the United Kingdom: lessons for prevention. $B M F$ 1992;304:1143-6.

3 Wintemute GJ. Childhood drowning and near drowning in the United States. Am $f$ Dis Child 1990;144:663-9.

4 Hassal IB. Thirty-six consecutive under 5 year old domestic swimming pool drownings. Aust Paediatr f 1989;25:143-6.

5 Wintemute GJ, Drake C. Immersion events in residential swimming pools. Am f Dis Child 1991:145:1200-3.

6 Pitt WR. Increasing incidence of childhood immersion injury in Brisbane. Med f Aust 1986;144:683-5.

7 Pearn J, Nixon J. Prevention of childhood drowning accidents. Med f Aust 1977;i:616-8.

8 Brill JE. Dispelling the myth of the "drownproof" child. Contemporary Pediatrics 1987 June: $30-43$.

9 Sibert JR. Accidents to children: the doctor's role. Education or environmental change? Arch Dis Child 1991;66:890-3.

10 Wigglesworth EC. The fault doctrine and injury control. $f$ Trauma 1978;18:789-94.

11 Baker SP. Prevention of childhood injuries. Med $\mathcal{F}$ Aust 1980;i:466-70.

12 Pitt WR, Balanda KP. Childhood drowning and near-drowning in Brisbane: the contribution of domestic pools. Med f Aust 1991;154:661-5.

13 Harris AH, Warchiver I, deKlerk N. A review of proposed legislative changes to reduce pre-school child drownings in western Australia - a final report to the Health Department of western Australia. Perth: University of Western Australia, 1991.

14 Cass DT, Ross FI, Grattan-Smith TM. Child drownings: a changing pattern. Med f Aust 1991;154:163-5.

\section{Maternal "near miss" reports?}

\section{Difficulties in defining which cases to include}

Maternal mortality in the United Kingdom has now stabilised at around 7 per 100000 maternities (defined as pregnancy and up to 42 days post partum). Sixty years ago it was 400 per 100000 , and its dramatic reduction has been a remarkable achievement. ${ }^{1}$ Although better maternal health played a part, the fall was due not so much to socioeconomic factors as to improved maternity care in its widest sense.-1 ${ }^{1-3}$ Important contributions have been made by the Confidential Enquiries into Maternal Deaths.

Triennial reports on all maternal deaths in England and Wales began in 1952, and similar reports were issued in Northern Ireland from 1956 and in Scotland from 1965. Details about each case are collected on an anonymised form, which is reviewed by assessors in obstetrics, anaesthetics, and pathology and sent to a doctor at the Department of Health. A national panel of doctors classifies the cases according to cause of death and identifies avoidable factors. The forms are then destroyed. Obstetricians have learnt to trust this system, and, although the inquiry has no statutory powers, peer pressure ensures that collection is almost complete.

Because of falling numbers a single triennial report now covers all four countries in the United Kingdom. ${ }^{4}$ This reduces the risk that specific cases might be recognised. But a more fundamental problem with small numbers is that the report might be based on unusual events of little relevance to most women's maternity care. The report's attention to individual cases contrasts sharply with the statistical approach used by large randomised trials, though the principle of auditing single events is being extended to perinatal and infant deaths ${ }^{56}$ and to perioperative deaths. ${ }^{7}$

Might we obtain a more representative view of deficiencies in the maternity services by expanding the confidential inquiries to include "near misses?" Calls for research into medical accidents are increasing, ${ }^{8}$ and "critical incident" 